\title{
The LMDI-based Research on Chongqing's Carbon Emission of Energy Consumption
}

\author{
SUN Guiyan
}

(Chongqing Academy of Social Sciences, Chongqing 400020)

\begin{abstract}
Keywords: energy consumption; carbon emission; LMDI decomposition method; Chongqing.
Abstract: Based on Kaya identities, the LMDI decomposition method is used in building a factor decomposition model for Chongqing's carbon emission of energy consumption to perform empirical analysis on the impact of Chongqing's population, economic development, energy consumption structure, industrial structure and energy intensity on the carbon emission of energy consumption during 1997-2016. Researches show that the economic growth is a dominant factor of promoting the carbon emission per capita, the energy intensity is a dominant factor of inhibiting the carbon emission per capita, population has been a driving factor for the carbon emission per capita since 2010, and the impact of energy structure and industrial structure on the carbon emission per capita varies from proportion of coal consumption and proportion of industries. As a whole, the role of the driving factors is bigger than that of the inhibiting factors, resulting in overall increase of the carbon emission per capita. In the end, policy proposals shall be made to promote the carbon emission reduction.
\end{abstract}

\section{Introduction}

With increasingly global warming, reducing the carbon emission has become a global consensus. Particularly in recent years, with economically sustainable and rapid development and the increase of energy consumption, China has become the world's largest carbon emitter, with relatively-big pressure in the carbon emission reduction. To cope with greenhouse effect, under the framework of Treaty of Paris, China set forth a binding target that the carbon emission per unit of GDP in 2030 is $60 \%-65 \%$ lower than that in 2005. To this end, scholars rapidly increased researches into the carbon emission, by use of some factor decomposition methods and structural decomposition methods, such as Laspeyres index method, Fisher ideal index method, Logarithmic Mean Divisia Index (LMDI), random STIRPAT, etc. LMDI decomposition method is one of most widely-applied methods ${ }^{[1]}$, due to such problems as eliminating inexplicable residuals, and processing zero value and negative value, relatively-simple computational process, visual decomposition results, etc. Through its in-depth development, LMDI decomposition method decomposes the carbon emission increment into such sectors as population effect, economic scale effect, economic development level effect, industrial structure effect, energy intensity effect, energy consumption structure effect, etc. For example, Wang C. et al (2005), by use of LMDI decomposition method, comprehensively analyzes the impact of China's population, economic growth, energy intensity, and energy structure during 1957-2000 on the carbon emission ${ }^{[2] . ~ X U ~}$ Guoquan et $\mathrm{al}^{[3]}$ quantitatively analyzed the impact of the changes of such factors as energy structure, energy efficiency, economic development, etc. during 1995-2004 on China's carbon emission per capita. According to the research, the change of the economic factor produces a positive effect on the carbon emission, while the change of the energy intensity produces a negative effect on the carbon emission.

In view of remarkable difference between inter-regional economic and social development status and carbon emission in China, an appropriate energy conservation and emission reduction policy, based on the research into regional carbon emission status and influencing factors, contributes to achieving a marked effect in energy conservation and emission reduction at regional level. Therefore, more and more scholars, by use of LMDI decomposition method, have performed in-depth research into carbon emission characteristics, principal contradictions, different influencing factors of carbon emission, and intensity of effect in such regions as Beijing-Tianjin-Hebei ${ }^{[4]}$, the Yangtze River Economic Zone ${ }^{[5]}$, six provinces in central China ${ }^{[6]}$, etc., 
and such provinces and cities as Liaoning ${ }^{[7]}$, Jiangsu ${ }^{[8]}$, Guangdong ${ }^{[9]}$, Shandong ${ }^{[10]}$, Hebei ${ }^{[11]}$, Shaanxi ${ }^{[12]}$, etc., which are of practical significance to reasonably develop regional carbon emission reduction policy. Moreover, some of scholars also have performed the factor decomposition of carbon emission of such sectors as agriculture ${ }^{[13]}$, industry ${ }^{[14]}$, transportation industry ${ }^{[15]}$, land utilization $^{[16]}$, service industry ${ }^{[17]}$, etc., thereby revealing the impact of industrial changes on the carbon emission. So far, the researches on the carbon emission for China's various regions and industries are relatively abundant, and the application of LMDI decomposition model is increasingly mature, but the researches into the carbon emission of energy consumption for the provinces and cities in the West China are relatively rare; therefore, Chongqing, a rapidly-developed municipality in the West China, as research object, is performed decomposition analysis on characteristics of carbon emission change and influencing factors of carbon emission change, which provide scientific basis for Chongqing's low-carbon economic development.

Since 2014, Chongqing has ranked first in the GDP growth rate in several consecutive quarters. With economic and social rapid development, the total energy consumption was increased to 82,719,700T standard coal in 2016 from 20,301,300T standard coal in 1997, which also resulted in sharp increase of the carbon emission. In 2010, Chongqing became one of China's first low-carbon pilot cities, targeting at building a demonstration city in the green low-carbon development in the Southwest China. In 2017, Chongqing “The $13^{\text {th }}$ Five-Year Plan" Work Programme for Controlling Greenhouse Gas Emission proposed that Chongqing's carbon emission per unit of GRDP by the end of 2020 is at least $19.5 \%$ lower than that in 2015, and reaches peak before 2030, which is certain to result in big pressure in the carbon emission. Therefore, it needs to research and develop a feasible energy conservation and emission reduction strategy. Under such background, LMDI decomposition method is used in comprehensive quantitative analysis on Chongqing's carbon emission of energy consumption from such factors as population, economic growth, industrial structure, energy intensity, energy consumption intensity, technical development, etc. to reveal its mechanism and intensity, which provides references for Chongqing to develop appropriate carbon emission reduction policy and realize low-carbon development.

\section{Research method}

\section{Extended Kaya model}

Based on the previous researches, the extended Kaya model is used in decomposing Chongqing's carbon emission of energy consumption, which sets the influencing factors of carbon emission as such factors as population, economic growth, industrial structure, energy intensity, energy consumption structure, energy carbon emission, etc. Extended Kaya model expression is as follows:

$$
\mathrm{C}=\sum_{i} \sum_{j}\left(\frac{C_{i j}}{E_{i j}} \times \frac{E_{i j}}{E_{i}} \times \frac{E_{i}}{G D P_{i}} \times \frac{G D P_{i}}{G D P} \times \frac{G D P}{P O P} \times P O P\right)
$$

Where: $i$ is used in distinguishing type of industry, $j$ is used in distinguishing type of energy, $C$, $E, G D P$ and $P O P$ respectively represent carbon emission, energy consumption, Gross Domestic Product (GDP) and population. Otherwise:

$$
f_{i j}=\frac{C_{i j}}{E_{i j}} m_{i j}=\frac{E_{i j}}{E_{i}} e_{i}=\frac{E_{i}}{G D P_{i}} s_{i}=\frac{G D P_{i}}{G D P} a=\frac{G D P}{P O P} p=P O P
$$

Thus, the extended Kaya model can be expressed as:

$$
c=\sum_{i} \sum_{j}\left(f_{i j} \times m_{i j} \times e_{i} \times s_{i} \times a \times p\right)
$$

Where: $f_{i j}$ represents the carbon emission coefficient of the $j$ energy in the $i$ industry; $\boldsymbol{m}_{\mathbf{i} j}$ represents the consumption proportion of the $j$ energy in the $i$ industry; $\boldsymbol{e}_{\mathbf{i}}$ represents the energy 
consumption intensity of the $i$ industry; represents the proportion of the $i$ industry in GDP; $a$ represents GDP per capita; $p$ represents population. Total carbon emission in the formula (3) is expressed as carbon emission factor effect $\left(f_{i j}\right)$, energy structure effect $\left(\boldsymbol{m}_{i j}\right)$, energy intensity effect $\left(e_{i}\right)$, industrial structure effect $\left(s_{i}\right)$, economic growth effect $(a)$ and population effect $(p)$, which reflect the impact of carbon emission factors of various energies, energy consumption structure, energy consumption intensity, industrial structure, economic growth and population on the total carbon emission.

\section{LMDI decomposition method}

The additive decomposition method is used in decomposing the above factors; $\mathrm{C}^{0}$ ard $\mathrm{C}^{\mathrm{t}}$ are set as total carbon emissions of base period and thetperiod; comprehensive effect of carbon emissions:

$$
\Delta C=C^{t}-C^{0}=\Delta C_{f}+\Delta C_{m}+\Delta C_{a}+\Delta C_{s}+\Delta C_{a}+\Delta C_{p}
$$

Because the carbon emission coefficients of various energies are in general fixed, shall not be considered. So, the formula (4) can be simplified as:

$$
\begin{gathered}
\Delta C=\Delta C_{m}+\Delta C_{\mathrm{a}}+\Delta C_{s}+\Delta C_{a}+\Delta C_{p} \\
\mathrm{D}=\frac{C^{b}}{C^{\circ}}=D_{m} \times D_{a} \times D_{s} \times D_{a} \times D_{p} \\
\ln D=\ln D_{m}+\ln D_{a}+\ln D_{s}+\ln D_{a}+\ln D_{p}
\end{gathered}
$$

The contrasts (5) and (6) can be set corresponding proportions, that is:

$$
\begin{aligned}
& \frac{\ln D}{\Delta C}=\frac{\ln D_{m}}{\Delta C_{m}}=\frac{\ln D_{a}}{\Delta C_{a}}=\frac{\ln D_{s}}{\Delta C_{s}}=\frac{\ln D_{a}}{\Delta C_{a}}=\frac{\ln D_{p}}{\Delta C_{p}} \\
& \Delta C_{m}=\sum_{i=1} \sum_{j=1}\left(\frac{C_{i j}^{t}-C_{i}^{0}}{I n C_{i j}^{t}-I n C_{i j}^{o}} \times I n \frac{m_{i j}^{t}}{m_{i j}^{0}}\right) D_{m}=\Delta C_{m} \times \frac{\ln D}{\Delta C} \\
& \Delta C_{\mathrm{a}}=\sum_{i=1} \sum_{j=1}\left(\frac{C_{i j}^{t}-C_{i j}^{\circ}}{\operatorname{InC} C_{i j}^{t}-\operatorname{In} C_{i j}^{\circ}} \times \operatorname{In} \frac{e_{i j}^{t}}{e_{i j}^{0}}\right) D_{\mathrm{a}}=\Delta C_{\mathrm{a}} \times \frac{\ln D}{\Delta C} \\
& \Delta C_{s}=\sum_{i=1} \sum_{j=1}\left(\frac{C_{i j}^{t}-C_{i j}^{0}}{I n C_{i j}^{t}-I n C_{i j}^{0}} \times \operatorname{In} \frac{s_{i j}^{t}}{s_{i j}^{0}}\right) D_{s}=\Delta C_{s} \times \frac{\ln D}{\Delta C} \\
& \Delta C_{a}=\sum_{i=1} \sum_{j=1}\left(\frac{C_{i j}^{t}-C_{i j}^{o}}{\operatorname{In} C_{i j}^{t}-\operatorname{In} C_{i j}^{Q}} \times \operatorname{In} \frac{a_{i j}^{t}}{a_{i j}^{0}}\right) D_{a}=\Delta C_{a} \times \frac{\ln D}{\Delta C} \\
& \Delta C_{p}=\sum_{i=1} \sum_{j=1}\left(\frac{C_{i j}^{t}-C_{i j}^{0}}{\operatorname{InC} C_{i j}^{t}-\operatorname{In} C_{i j}^{0}} \times \operatorname{In} \frac{p_{i j}^{t}}{p_{i j}^{0}}\right) D_{p}=\Delta C_{p} \times \frac{\ln D}{\Delta C}
\end{aligned}
$$

where, $\Delta C_{f}$ and $D_{f}$ represent carbon emission factor effects; $\Delta C_{m} D_{m}$ represent energy structure effects; $\Delta C_{g}, D_{g}$ represent energy intensity effects; $\Delta C_{s}, D_{s}$ represent industrial structure effects; $\Delta C_{\mathrm{a}}$ and $D_{\mathrm{a}}$ represent economic growth effects; and $\Delta C_{p}$ and $D_{p}$ represent population effects. $\Delta C_{f}, \Delta C_{m}, \Delta C_{a}, \Delta C_{g}, \Delta C_{a}$ and $\Delta C_{p}$ represent the contribution value of the changes of factors to the change of the carbon emission per capita, $D_{f}, D_{m}, D_{g}, D_{s}, D_{a}$ and $D_{p}$ represent the contribution rate of the changes of factors to the change of the carbon emission per capita.

The required data for the accounting of Chongqing's carbon emission of energy consumption and the research into influencing factors of carbon emission of energy consumption are derived from Chongqing Statistical Yearbook (1998-2017) and China Energy Statistical Yearbook 
(1998-2016). The carbon emission coefficients and conversion standard coal coefficients of various energies in the calculation of carbon emissions respectively refer to 2006 IPCC Guidelines for National Greenhouse Gas Inventories and China Energy Statistical Yearbook.

Table 1 Carbon Emission Coefficients of Various Energies

\begin{tabular}{|c|c|c|c|c|c|}
\hline Types & $\begin{array}{c}\text { Conversion standard } \\
\text { coal coefficient (kg ce / } \\
\text { physical quantity) }\end{array}$ & $\begin{array}{l}\text { Emission } \\
\text { coefficient } \\
\left(\mathrm{tco}_{2} / \text { tce }\right) \\
\end{array}$ & Types & $\begin{array}{l}\text { Conversion } \\
\text { standard coal } \\
\text { coefficient } \\
\end{array}$ & $\begin{array}{l}\text { Emission } \\
\text { coefficient } \\
\left(\mathrm{tco}_{2} / \mathrm{tce}\right) \\
\end{array}$ \\
\hline Crude coal & 0.7143 & 0.7559 & Crude oil & 1.4286 & 0.5857 \\
\hline $\begin{array}{l}\text { Cleaned } \\
\text { coal }\end{array}$ & 0.9 & 0.7559 & Gasoline & 1.4714 & 0.5538 \\
\hline $\begin{array}{c}\text { Other } \\
\text { cleaned coal }\end{array}$ & 0.2857 & 0.7559 & Kerosene & 1.4714 & 0.5714 \\
\hline Briquette & 0.6 & 0.7559 & Diesel & 1.4571 & 0.5912 \\
\hline Coke & 0.9714 & 0.8550 & Fuel oil & 1.4286 & 0.6185 \\
\hline $\begin{array}{l}\text { Coke-oven } \\
\text { gas }\end{array}$ & 0.5714 & 0.3548 & $\begin{array}{l}\text { Other } \\
\text { petroleum } \\
\text { products }\end{array}$ & 1 & 0.5857 \\
\hline $\begin{array}{c}\text { Blast-furnac } \\
\text { e gas }\end{array}$ & 1.286 & 0.3548 & $\begin{array}{c}\text { Liquefied } \\
\text { petroleum gas }\end{array}$ & 1.7143 & 0.5042 \\
\hline $\begin{array}{l}\text { Other coal } \\
\text { gas }\end{array}$ & 0.6 & 0.3548 & Natural gas & 1.33 & 0.4483 \\
\hline $\begin{array}{l}\text { Other coke } \\
\text { chemicals }\end{array}$ & 1.1 & 0.6449 & $\begin{array}{l}\text { Hydro power } \\
\text { and nuclear } \\
\text { power }\end{array}$ & 0.1229 & 0.0 \\
\hline
\end{tabular}

\section{Research findings}

With Chongqing's economic and social rapid development, the increasing demands on the energy consumption also result in the increase of Chongqing's carbon emission. The total energy consumption was increased to 82,719,700tce in 2016 from 20,301,300tce in 1997, increasing 4.07 times. Moreover, the total carbon emission was increased to 46,458,300t in 2016 from 12,581,300t in 1997, increasing 3.69 times, with annual average growth rate of 7.12\%. The increasing ranges of the two are roughly the same. As seen from Fig. 1, Chongqing's total carbon emission and carbon emission per capita during 1997-2016 tended to be continuously overall increase; the carbon emission per capita was increased to 1.52 ton/person in 2016 to 0.44 ton/person in 1997, increasing 3.48 times. The increasing range is far beyond national average. Chongqing has relatively-big pressure in the carbon emission reduction.

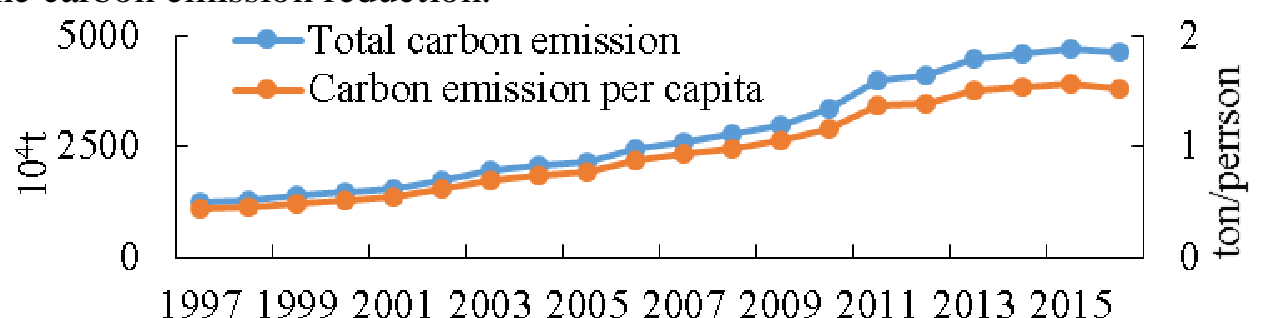

Fig.1 Chongqing's Total Carbon Emission and Carbon Emission per Capita during 1997-2016

In terms of Chongqing's carbon emission of various sectors, although carbon emissions of such sectors as transportation, storage and post are relatively small, there is the largest increasing range from 268,400t in 1997 to 4,578,000t in 2015, increasing 17.06 times. For agriculture, forestry, husbandry, fishery and water conservancy industry, with the implementation of Chongqing "Action Blue Sky", and the reinforcement of preventing pollution from livestock and poultry and pollution of water bodies, etc., Chongqing's carbon emission was increased to 2,295,800t in 2012 from $1,025,800 \mathrm{t}$ in 1997 , and then decreased to $492,900 \mathrm{t}$ in 2015 , with a tendency of increasing at first 
and then decreasing sharply. Optimization and upgrading of industrial structure arising from the development of Chongqing's electronic information industry, issuance of the stricter provisions such as Chongqing's Standard for Comprehensive Emission of Air Pollutants, Chongqing's Regulations on Access of Industrial Environment Projects, etc., and vigorous promotion of such projects as electric power replacement, contribute to the tendency of zigzag change in the carbon emission of Chongqing's industrial sectors. Chongqing's carbon emission was increased to 19,884,800t in 2015 from 8,457,900t in 1997, increasing 2.35 times. The increasing range of the carbon emission is relatively smaller than that of the industrial added value (increasing 9.79 times during 1997-2015). The carbon emissions of construction industry, wholesale, retail, accommodation and catering industry have been increasing steadily. Moreover, the carbon emission of living consumption and other sectors has relatively-high increase, from 2,748,500T in 1997 to $21,357,600 \mathrm{~T}$ in 2016, increasing 7.77 times.

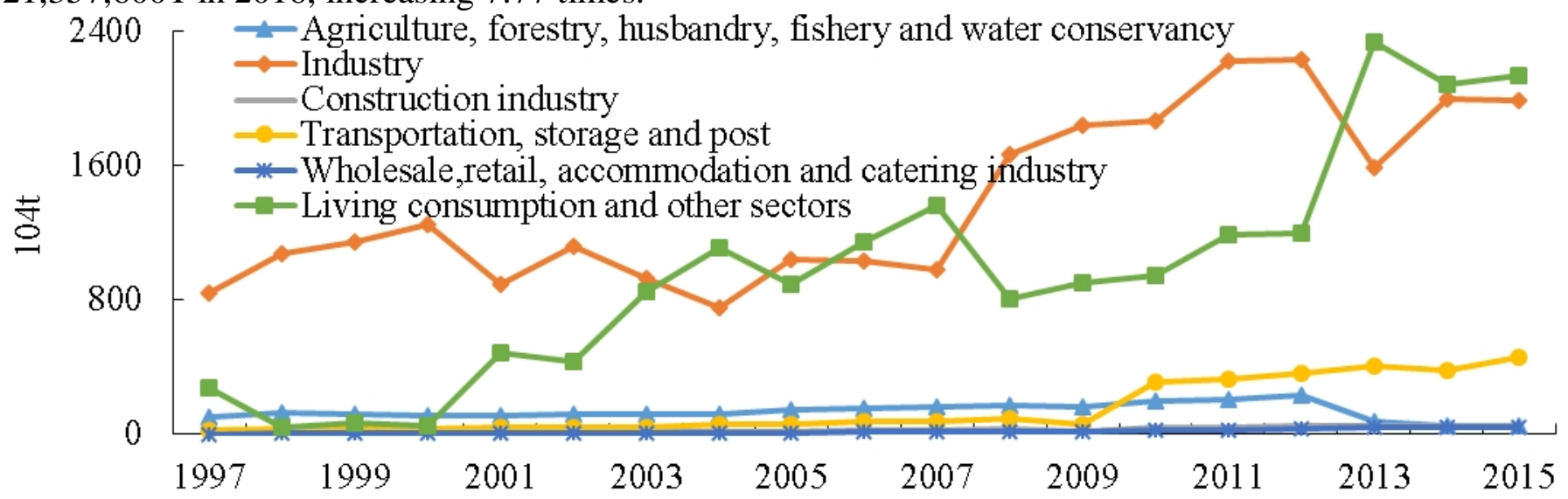

Fig. 2 Carbon Emissions of Various Sectors

With the year 1997 as the base period, extended Kaya model and LMDI decomposition method are used in performing the decomposition analysis on Chongqing's carbon emission of energy consumption during 1997-2016. Specific findings can be seen in Fig. 3, Fig. 4, Fig. 5 and Fig. 6.

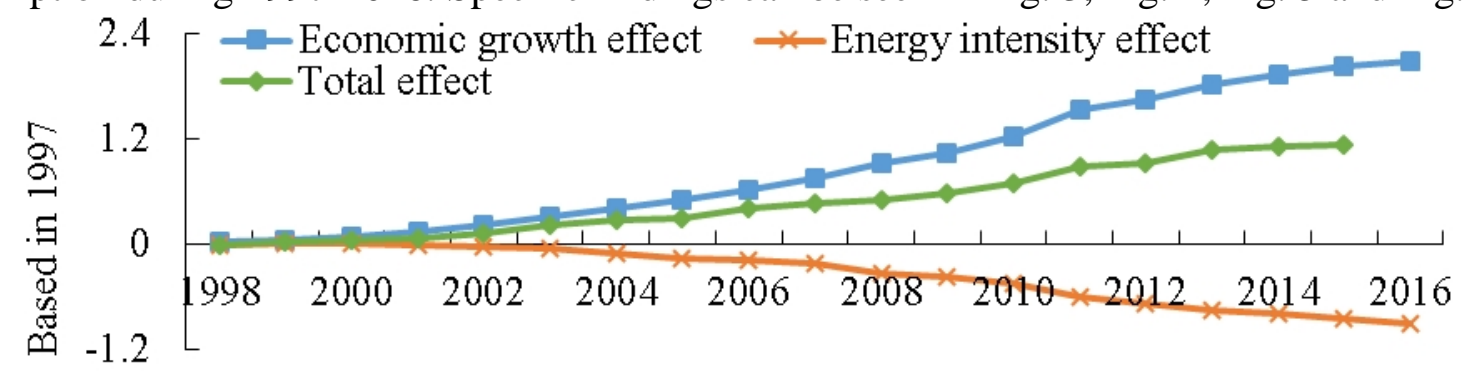

Fig. 3 Trend Chart for Contribution Value of Economic Growth and Energy Intensity Effect to Chongqing's Carbon Emission per Capita during 1998-2016

(1) Total effect of Chongqing's carbon emission per capita tends to increase continuously. The economic growth effect has the biggest impact, followed by the energy intensity effect.

(2) The contribution value of the economic growth effect to Chongqing's carbon emission per capita has always been a positive value, and tends to increase steadily, which indicates that the sustained economic growth evidently boosts the increase of the carbon emission per capita. Moreover, the contribution rate of the economic growth to Chongqing's carbon emission per capita tends to be an exponential increase, and the contribution rates to the increase of the carbon emission per capita during different periods are higher than the inhibiting effect of other factors to Chongqing's carbon emission per capita, thereby resulting in the increase of Chongqing's carbon emission per capita. 


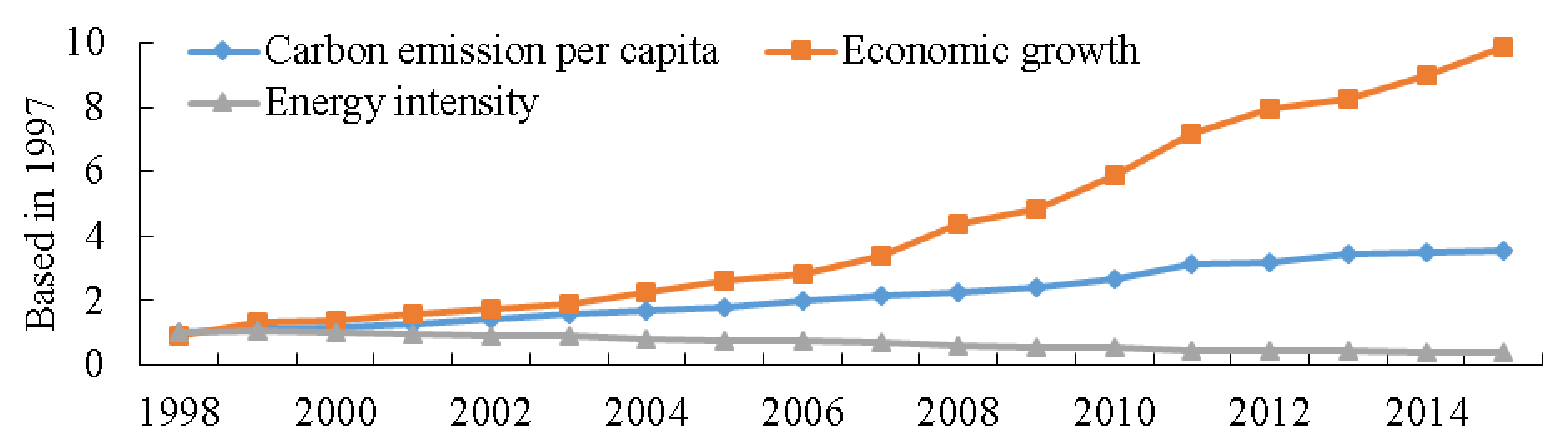

Fig. 4 Trend Chart for Contribution Rate of Economic Growth and Energy Intensity Effect to Chongqing's Carbon Emission per Capita during 1998-2016

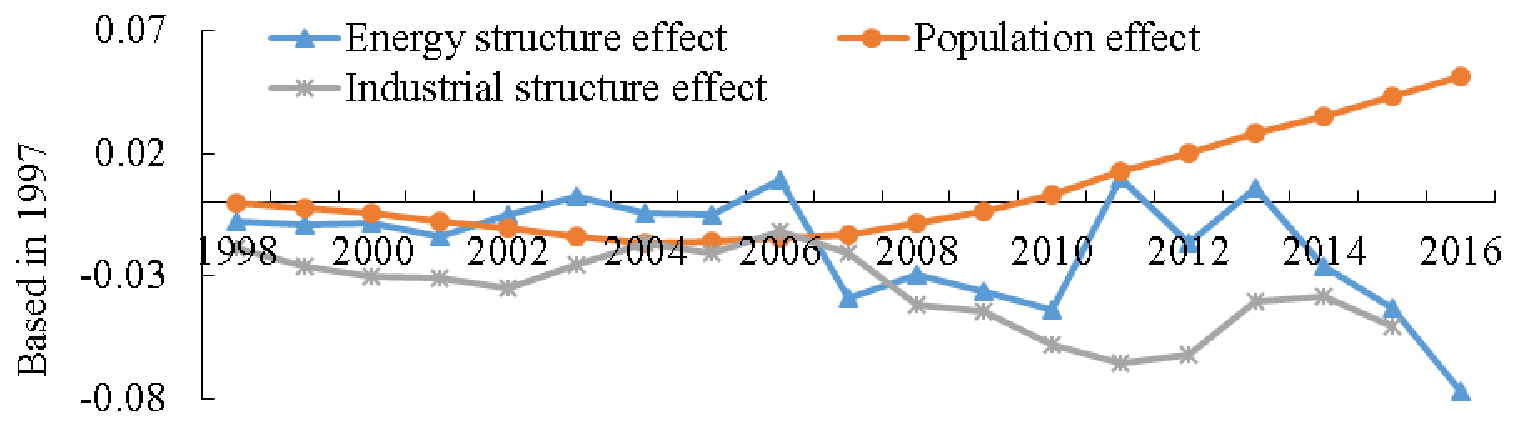

Fig. 5 Trend Chart for Contribution Value of Energy Structure Effect, Population Effect and Industrial Structure Effect to Chongqing's Carbon Emission per Capita

(3) The contribution value of energy intensity effect and industrial structure effect to Chongqing's carbon emission per capita is a negative value, which indicates that the energy intensity and industrial structure inhibit the increase of the carbon emission per capita. The contribution value of the industrial structure effect to the carbon emission per capita tends to be fluctuant, and its changing trend is basically consistent with that of the proportion of industrial added value in GDP. The contribution value of the energy intensity effect to the carbon emission per capita and the contribution rate of the energy intensity effect to the carbon emission per capita tend to decrease, which indicates that the enhancement of the energy efficiency can inhibit the increase of the carbon emission. In recent years, the growth rate of contribution value of the energy intensity effect to the carbon emission per capita was relatively higher that of the economic growth, which to some extent results in slowness, even reduction of the growth rate of Chongqing's carbon emission per capita.

(4) The population effect can measure the impact of change of regional population on the carbon emission per capita. The contribution value of the population effect to Chongqing's carbon emission per capita was a positive value initially, and then a negative value since 2010 , and tends to increase, which indicates that the change of population inhibits and then drives the increase of Chongqing's carbon emission per capita. Moreover, the contribution rate of population to the carbon emission per capita tends to be U-shaped. The reason is that Chongqing's permanent population were decreased and then increased, and till 2010 exceeded the population when Chongqing became a municipality. Increase of population size, enhancement of urbanization level and change of consumption mode contribute to expansion of energy demands on production and living, which to some extent increase the carbon emission. 


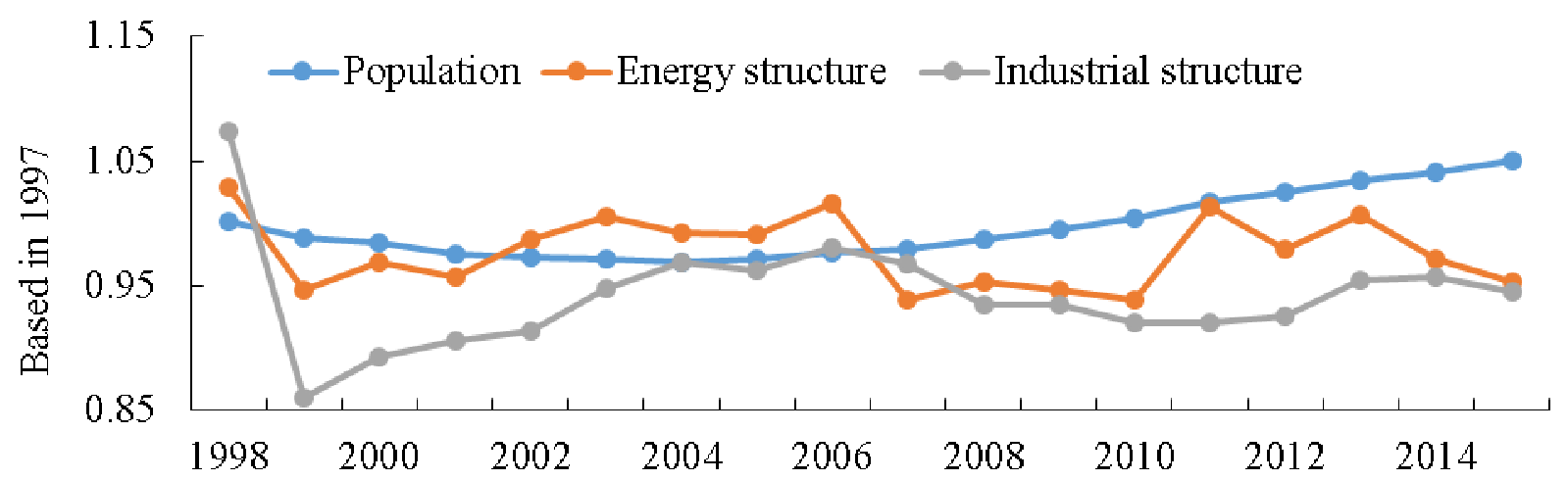

Fig. 6 Trend Chart for Contribution Rate of Energy Structure Effect, Population Effect and Industrial Structure Effect to Chongqing's Carbon Emission per Capita

(5) The energy structure effect is highly fluctuant, and was positive in 2003, 2006, 2011 and 2013, and negative in the other years. The changing trend of the contribution value of the energy structure to Chongqing's carbon emission per capita is consistent with that of the contribution rate of the energy structure to Chongqing's carbon emission per capita. Such changing trend is consistent with that of the proportion of coal in the energy consumption.

\section{Conclusions and countermeasures}

Chongqing's carbon emission per capita tends to increase on the whole, and has increased slowly, even decreased in recent years. In terms of Chongqing's carbon emission per capita, the economic growth is a dominant factor to boost the increase of the carbon emission per capita, and the driving effect of the economic growth to the increase of the carbon emission per capita is higher than the inhibiting effect of other factors to Chongqing's carbon emission per capita; the energy intensity is a dominant factor to inhibit the increase of the carbon emission per capita; the population was an inhibiting factor at first, and then a driving factor since 2010. Coal-dominated energy structure and industry-dominated industrial structure fluctuate the carbon emission per capita with the change of consumption proportion.

Therefore, due to continuous increase of Chongqing's carbon emission per capita, Chongqing shall fully mine advantageous resources in tourism, culture, geographical location, etc., vigorously develop tertiary industry, adjust industrial inner structure, vigorously develop low-consumption low-pollution industries such as electronic information industry, and realize optimization and upgrading of industrial structure; strengthen inspection and evaluation over the carbon emissions of various sectors, strictly control over-fast increase of high-consumption industries; accelerate the promotion of such projects as power replacement, increase the proportion of natural gas, hydropower and solar energy in consumption, and change coal-dominated energy structure, strengthen introduction of new and high energy-saving technologies and research and development fund and policy support, boost industry-university-institute cooperation, and eliminate low-consumption low-efficiency backward processing technologies to enhance efficiency of energy utilization; enhance publicity on green travel and low-carbon life via network, TV, broadcasting, etc., and raise awareness of low carbon.

\section{References}

[1] Ang B W . Decomposition analysis for policymaking in energy: Which is the preferred Mehod ?

[J ] . Energy Policy , 2004 , 32( 9) : 1131-1139.

[2] Wang C ,Chen J ,Zou J .Decomposition of energy - related CO2emission in China: 1957 - 2000

[ J ] . Energy , 2005, 30( 1): 73-83 .

[3] X. Guoquan, L Zeyuan, J. Zhaohua. Decomposition model and empirical study of carbon emissions for China, 1995-2004 [J]. China Population Resources and Environment, 2006, 16(6): 
158-161.

[4] W. Zheng, L. Xiao, Z. Yongbin, et al,. Prediction on Beijing's, Tianjin's and Hebei's carbon emission [J]. Geography and Geo-Information Science, 2012, 28(1): 84-89.

[5] H. Qin, H. Qing. Driving Factors AND Spatial Characteristics of Carbon Emissions in Yangtze River Economic BELT Based on LMDI Model [J]. Finance and Economics, 2017 (5): 80-92.

[6] L Chuanjiang, H. Guiran, Z. Ming. Influencing factor decomposition of carbon emission of six provinces in central China [J]. Technology Economics, 2013, 32(1): 101-105.

[7] Y. Peng, C. Shi. The drivers of $\mathrm{CO}_{2}$ emission growth in Liaoning province and empirical research based on LMDI [J]. Journal of Dalian University of Technology (Social Sciences), 2012 (1): 35-40.

[8] H. Chuzhi, H. Xianjin, Z. Taiyang, et al. Character of carbon emission in China and Its Dynamic Development Analysis [J]. China Population Resources and Environment, 2008, 18(3): 38-42.

[9] Q. Yi, H. Li. Decomposition Analysis on $\mathrm{CO}_{2}$ Emission from Energy Consumption in Guangdong Province Based on LMDI Method [J]. Science and Technology Management Research, 2013, 33(12): 224-227.

[10] S. Jiekun. Factor Decomposition of Carbon Emissions from Energy Consumption of Shandong Province Based on LMDI [J]. Resources Science, 2012, 34(1):35-41.

[11] W. Caiming, LI Jian. Empirical Analysis of Carbon Emission Accounting and Influencing Factors of Energy Consumption in Hebei Province Based on LMDI Model [J]. Science and Technology Management Research, 2017 (10): 258-266.

[12] Z. Wei, Z. Jinsuo, Z. Shaohui, X. Jian. Factor decomposition of carbon emissions from energy consumption of Shaanxi province based on LMDI [J]. Journal of Arid Land Resources and Environment, 2013, 27(9): 26-31.

[13] L. Guozhi, L. Zongzhi. Carbon emissions decomposition analysis on agricultural energy consumption-based LMDI model [J]. Journal of Agrotechnical Ecnomics, 2010 (10): 66-72.

[14] W. Naiju, H. Xiang. Intensity and effect of industrial carbon emissions in Langzhou city [J]. Acta Scientiae Circumstantiae, 2016, 36(6): 2242-2251.

[15] Y. Chang-wei, L. Ruo-ying, R. Xiao-li, B. Juan. Decomposition of the impact factors of carbon emission in Shaanxi transportation industry [J]. Journal of Chang'an University ( Social Science Edition), 2016, 18(2): 38-42.

[16] C. JiangLong, L. PingXing, G. JinLong. 2016. Spatiotemporal patterns and influencing factors of carbon emissions in the Pan-Yangtze River Delta region, 1990-2014[J]. Progress in Geography, 35(12): 1472-1482.

[17] W. Kai, L. Juan, T. Yu-ling, L. Haolong. Carbon Emissions Accounting and Decomposition Analysis of Energy Consumption of Service Industry in China [J]. China Population Resources and Environment, 2013, 23(5): 21-28. 